\title{
Outcome after Stroke upon Awakening
}

\author{
Janel O. Nadeau, Jiming Fang, Moira K. Kapral, Frank L. Silver, \\ Michael D. Hill on behalf of the investigators for the \\ Registry of the Canadian Stroke Network
}

\begin{abstract}
Background: An estimated 20-25\% of all strokes occur during sleep and these patients wake up with their deficits. This study evaluated outcomes among patients who woke up with stroke compared to those who were awake at stroke onset. Methods: Using data from the Registry of the Canadian Stroke Network Phases 1 and 2, we compared demographics, clinical data and six-month outcomes between patients with stroke-on-awakening versus stroke-while-awake. Strokes of all types (ischemic stroke, transient ischemic attack, intracerebral hemorrhage and subarachnoid hemorrhage) were included. Standard descriptive statistics, multivariable logistic regression and general linear modeling were applied to the data to compare variables. Results: Among 2,585 stroke patients, $349(13.5 \%)$ woke up with stroke and 2,236 (86.5\%) did not. Patients with stroke-on-awakening were more likely to have higher blood pressure and to suffer ischemic stroke, but stroke severity, measured by level of consciousness, did not differ. Mortality both at discharge and at six-month follow-up did not differ between the two cohorts. However, patients with stroke-on-awakening were less likely to return home, and their median Stroke Impact Scale-16 scores were 7.0 points lower compared to those with stroke-while-awake. Conclusions: There are minor demographic and clinical differences between patients with stroke-on-awakening and stroke-whileawake. Functional outcomes are slightly worse among patients with stroke-on-awakening, an effect which was driven by poor outcomes among patients with subarachnoid hemorrhage.
\end{abstract}

RÉSUMÉ: Issue chez les patients qui constatent au réveil qu'ils ont subi un accident vasculaire cérébral. Introduction: Environ 20 à $25 \%$ de tous les accidents vasculaires cérébraux (AVC) surviennent pendant le sommeil et le patient constate le déficit à son réveil. Cette étude évalue l'issue chez ces patients par rapport à ceux qui étaient éveillés au moment du début de leur AVC. Méthodes: Nous avons comparé les données démographiques, les données cliniques et l'issue à six mois chez ces deux groupes de patients identifiés par le Registry of the Canadian Stroke Network phase 1 et 2. Les patients ayant subi un AVC de tous types ont été inclus (AVC ischémique, ischémie cérébrale transitoire, hémorragie intracérébrale et hémorragie sous-arachnoïdienne). La comparaison des variables a été effectuée au moyen des procédures statistiques descriptives standard, de l'analyse de régression logistique multivariée et de la modélisation linéaire générale. Résultats: 349 (13,5\%) des 2,585 patients atteints d'AVC ont constaté le déficit dû à l'AVC au réveil alors que chez les 2,236 (86,5\%) autres l'AVC est survenu pendant que le patient était éveillé. Les patients atteints d'AVC au réveil étaient plus susceptibles d'avoir une tension artérielle plus élevée et d'être atteints d'un AVC ischémique. La sévérité de l'AVC, mesurée par le niveau de conscience, et la mortalité à la sortie de l'hôpital et à six mois, étaient les mêmes dans les deux groupes. Cependant, la probabilité du retour à domicile était moindre chez les patients atteints d'AVC au réveil et leur score médian au Stroke Impact Scale-16 était plus faible de 7,0 points par rapport à celui des patients dont l'AVC est survenu pendant la période d'éveil. Conclusions: Il existe des différences démographiques et cliniques mineures entre les patients ayant constaté l'AVC au réveil par rapport à ceux dont l'AVC est survenu en période d'éveil. L'issue fonctionnelle est légèrement moins bonne chez les patients qui constatent l'AVC au réveil, une constatation due en grande partie à l'issue moins favorable des patients ayant subi une hémorragie sous-arachnoïdienne.

Can. J. Neurol. Sci. 2005; 32: 232-236

As many as $20-25 \%$ of all ischemic strokes occur during sleep. ${ }^{1,2}$ The actual time of stroke onset is unknown and the "last seen well" principle is applied so that stroke onset is dated from when the patient was last observed well. Most often, this is the time that they retired for bed. If the patient has awoken or arisen during the night, they are often unwitnessed or inaccurately witnessed so that it is not clear whether a particular deficit was present. For example, the patient who presents with aphasia may not have spoken to anyone in the middle of the night.

Strokes most commonly occur between six a.m. and noon, ${ }^{1-4}$ and one study found that $24 \%$ of ischemic strokes happen in the first hour upon awakening. ${ }^{5}$ This may, in part, be due to normal circadian rhythms with blood pressure, cortisol levels and platelet aggregation peaking in the early morning., ${ }^{4-6}$ The corollary may be that a substantial portion of patients who wake up with their stroke have actually just recently suffered their event.

Two previous studies, involving a total of 1,612 patients, have

From the Calgary Stroke Program, Department of Clinical Neurosciences, University of Calgary, Calgary, AB, Canada.

RECEIVED SEPTEMBER 28, 2004. ACCEPTED IN FINAL FORM JANUARY 28, 2005. Reprint requests to: Michael D. Hill, Calgary Stroke Program, Department of Clinical Neurosciences, University of Calgary, Foothills Hospital, Rm 1242A, 1403 29th Street NW, Calgary, Alberta, T2N 2T9 Canada. 
shown that there are no significant differences in clinical characteristics, including stroke severity, among patients that present with stroke-on-awakening versus stroke-while-awake., ${ }^{2,9}$ Similarly, there are no differences in characteristics of nighttime versus daytime strokes. ${ }^{10}$ In the current era of treatment windows defined by time, patients with stroke-on-awakening are most often excluded from thrombolytic therapy or involvement in clinical trials of new acute stroke therapies. However, such patients may be eligible for treatment based on magnetic resonance imaging or computerized tomography window of brain perfusion independent of time, if identified safely. Fink et al., using diffusion-weighted imaging and perfusion-weighted imaging, showed that lesion volumes were similar between patients who did and did not wake up with stroke. ${ }^{9}$ They also demonstrated that $73 \%$ of nonlacunar strokes beyond the threehour time window showed perfusion-weighted imaging/ diffusion-weighted imaging mismatch. Outcomes among patients with stroke-on-awakening have not been previously examined.

Our primary objective was to examine outcomes among patients that present with stroke-on-awakening versus strokewhile-awake. A secondary objective was to understand whether a population of patients exists who might be eligible for thrombolysis despite an unknown time of onset.

\section{Methods}

Data were from Phase 1 and Phase 2 of the Registry of the Canadian Stroke Network (RCSN). The RCSN is a prospective registry of consecutive patients with stroke or transient ischemic attack from across Canada, described previously. ${ }^{11,12}$ The data include detailed demographic, historical, and clinical data as well as outcome at six months. A signed, informed consent process was used, limiting the registry to about $40 \%$ of the potentially eligible patients. As part of the data collection, the nurse co-ordinator at each site both identified if the patient's stroke deficits were first noticed upon awakening and determined the time last seen well. All stroke types (ischemic stroke, transient ischemic attack, intracerebral hemorrhage and subarachnoid hemorrhage) were eligible for inclusion in this study.

We evaluated three major outcomes: discharge mortality, mortality at six months, and for those patients who were alive at six months, the Stroke Impact Scale-16 score (SIS-16). ${ }^{13}$ The SIS-16 is designed to measure physical functioning and was chosen because it measures stroke-specific disability. It is sensitive to differences in physical functioning and has wellvalidated psychometric properties. ${ }^{14}$ The SIS-16 is derived from the Stroke Impact Scale, ${ }^{15}$ and the details are described previously. Each question is rated on a scale of 1 (could not do at all) to 5 (not difficult at all), and the combined scores are then transformed to a score from 0 (worst) to 100 (best) using the same algorithm as the Stroke Impact Scale. ${ }^{16}$

\section{Statistical methods}

The study cohort was characterized using standard descriptive statistics. The means of numeric variables were tested for significance using t-tests, and the median using the Kruskal-Wallis test. For categorical variables, the singular p- value corresponds to a Chi-square test. The significance level for all tests was 0.05. Multivariable logistic regression was used to assess mortality between the two cohorts, while adjusting for known confounders. General linear modeling was used to assess differences in the SIS-16 between the two cohorts. Assessments were made for the entire cohort and then by stroke type.

\section{Results}

\section{Demographics and medical history}

A total of 3,449 consenting stroke patients were enrolled in Phase 1 and 2 of the RCSN. If the event was diagnosed as a nonstroke, or if it was unknown whether the stroke event occurred upon awakening or while awake, we omitted them from our study. The timing of stroke ("last seen well" time) was unclear in 347 additional patients and they were also excluded. Among a final sample of 2,585, 349 (13.5\%) patients woke up with their deficits, and 2,236 (86.5\%) patients did not. Baseline variable data are presented in Table 1. Patients with stroke-on-awakening were more likely to be older, to be smokers and to be Asian.

\section{Clinical data}

Of the patients with a known onset time, $13.5 \%$ received thrombolysis, compared with $2.1 \%$ for patients with stroke-onawakening. Canadian Neurological Scale scores were collected in Phase 2, and among 1,226 patients, the median score was 9.0 among patients with stroke-on-awakening and 9.5 among patients with stroke-while-awake $(\mathrm{p}=0.0501)$. Patients with stroke-on-awakening were more likely to have a higher systolic blood pressure and to suffer ischemic stroke. [Table 2].

\section{Outcome}

Outcome data at discharge and at six months are presented in Table 3. Initial mortality data were available for all but four patients $(n=2,581)$. Overall discharge mortality was $6.5 \%$, with no significant difference between the two cohorts. At six months, the vital status on 1,947 (75.3\% overall) patients was known with $5.2 \%$ mortality. This also did not differ between groups. Overall, the median SIS-16 score at six months was 7.0 points lower in stroke-on-awakening patients; however, this difference was 5.1 points after adjustment for gender, age and level of consciousness.

Patients with stroke-on-awakening were significantly more likely to be transferred to an inpatient rehabilitation facility (59.7\% versus $44.0 \%)$ or some type of continuing care facility ( $16.8 \%$ versus $8.9 \%$ ), and consequently less likely to return home $(20.2 \%$ versus $44.7 \%$, $\mathrm{p}=0.0001)$. Length of stay between groups was not significantly different, at a median of 11 days compared to ten days for stroke-on-awakening and stroke-whileawake patients respectively.

\section{Predictors of death}

Using mortality at six months, we developed a backwards elimination logistic regression model to identify independent predictors of death. We used level of consciousness as a surrogate for stroke severity. ${ }^{17,18}$ Level of consciousness at admission as well as age were included as forced variables in the model. Increased age $(\mathrm{p}<0.0001)$ and whether the patient was initially unconscious versus alert $(\mathrm{p}=0.0324)$ were found to be 


\section{Table 1: Baseline Characteristics}

\begin{tabular}{|c|c|c|c|c|}
\hline Variables & Overall & Stroke-on-Awakening & Stroke-While-Awake & P-value \\
\hline \multicolumn{5}{|l|}{ DEMOGRAPHICS: } \\
\hline Sample size (n) & 2585 & 349 & 2236 & \\
\hline Median Age (y) & 71 & 73 & 71 & 0.0513 \\
\hline Gender ( $\%$ Female) & 45.5 & 43.6 & 45.8 & 0.443 \\
\hline Ethnic origin $(\%)$ & & & & 0.0001 \\
\hline Caucasian & 85.0 & 88.5 & 84.5 & \\
\hline Asian & 2.9 & 6.3 & 2.4 & \\
\hline East Indian & 2.4 & 2.4 & 2.4 & \\
\hline African & 0.7 & 1.0 & 0.6 & \\
\hline Caribbean & 0.6 & 0.0 & 0.7 & \\
\hline Aboriginal & 0.5 & 0.3 & 0.6 & \\
\hline Pacific Islander & 0.4 & 0.0 & 0.5 & \\
\hline Hispanic & 0.2 & 0.3 & 0.2 & \\
\hline Other or Undetermined & 7.2 & 1.0 & 8.1 & \\
\hline \multicolumn{5}{|l|}{ HISTORICAL: } \\
\hline Atrial Fibrillation (\%) & 14.0 & 15.9 & 13.7 & 0.1162 \\
\hline Diabetes (\%) & 21.7 & 24.9 & 21.2 & 0.2948 \\
\hline Smoked $(\%)$ & 44.6 & 51.2 & 43.6 & 0.0016 \\
\hline Current smoker (\%) & 19.6 & 19.8 & 19.6 & 0.7797 \\
\hline Hyperlipidemia (\%) & 30.1 & 34.7 & 29.4 & 0.1212 \\
\hline Previous Stroke or TIA (\%) & 31.7 & 32.7 & 31.5 & 0.6767 \\
\hline Hypertension (\%) & 58.6 & 63.2 & 57.9 & 0.1503 \\
\hline CHF or Pulmonary Edema (\%) & 5.1 & 5.8 & 5.0 & 0.563 \\
\hline
\end{tabular}

TIA, transient ischemic attack; CHF, congestive heart failure.

Table 2: Clinical Data

\begin{tabular}{|c|c|c|c|c|}
\hline Variables & Overall & Stroke-on-Awakening & Stroke-While-Awake & P-value \\
\hline Level of Consciousness (\%) & & & & 0.6787 \\
\hline Alert & 82.8 & 84.7 & 82.5 & \\
\hline Confused & 3.9 & 4.0 & 3.9 & \\
\hline Drowsy & 7.1 & 5.8 & 7.3 & \\
\hline Unconscious & 6.2 & 5.5 & 6.4 & \\
\hline Mean Arterial Pressure (mm Hg) & 109.1 & 111 & 108.7 & 0.0343 \\
\hline Median Blood Pressure (mm Hg) & $157 / 82$ & $160 / 82$ & $157 / 82$ & 0.0144 \\
\hline Median Glucose (mmol/L) & 6.6 & 6.5 & 6.6 & 0.9305 \\
\hline Stroke Type (\%) & & & & 0.0001 \\
\hline AIS & 72.2 & 83.3 & 70.5 & \\
\hline $\mathrm{ICH}$ & 9.9 & 6.3 & 10.4 & \\
\hline TIA & 8.0 & 2.9 & 8.8 & \\
\hline SAH & 7.1 & 3.5 & 7.7 & \\
\hline SVT & 0.3 & 0.3 & 0.2 & \\
\hline Undetermined & 2.5 & 3.7 & 2 & \\
\hline OCSP Stroke Subtype (\%) & & & & 0.0003 \\
\hline LACS & 15.1 & 21.1 & 14.2 & \\
\hline PACS & 33.2 & 37.9 & 32.6 & \\
\hline POCS & 20.2 & 21.8 & 19.9 & \\
\hline TACS & 10.9 & 7.7 & 11.4 & \\
\hline TIA & 13.3 & 6.3 & 14.4 & \\
\hline Undetermined or Other & 7.3 & 5.2 & 7.5 & \\
\hline
\end{tabular}

AIS, acute ischemic stroke; ICH, intracerebral hemorrhage; SAH, subarachnoid hemorrhage; SVT, sinovenous thrombosis; LACS, lacunar syndrome; PACS, partial anterior circulation syndrome; POCS, posterior circulation syndrome; TACS, total anterior circulation syndrome. 


\section{Table 3: Outcome}

\begin{tabular}{|c|c|c|c|c|c|}
\hline Variables & $\mathbf{n}$ & Overall (\%) & $\begin{array}{c}\text { Stroke-on- } \\
\text { Awakening (\%) }\end{array}$ & $\begin{array}{l}\text { Stroke-While- } \\
\text { Awake (\%) }\end{array}$ & P-value \\
\hline $\begin{array}{l}\text { Residence of Alive Patients } \\
\text { Home } \\
\text { In-Patient Rehab } \\
\text { Continuing Care } \\
\text { Other }\end{array}$ & 1657 & $\begin{array}{c}41.2 \\
46.2 \\
10.0 \\
2.6\end{array}$ & $\begin{array}{c}20.2 \\
59.7 \\
16.8 \\
3.3\end{array}$ & $\begin{array}{c}44.7 \\
44.0 \\
8.9 \\
2.4\end{array}$ & 0.0001 \\
\hline $\begin{array}{l}\text { Mortality } \\
\text { on Discharge } \\
\text { at } 6 \text { months } \\
\text { Median SIS-16 at } 6 \text { months }\end{array}$ & $\begin{array}{l}2581 \\
1947 \\
1620\end{array}$ & $\begin{array}{c}6.5 \\
5.2 \\
89.1\end{array}$ & $\begin{array}{c}6.6 \\
6.3 \\
83.6\end{array}$ & $\begin{array}{c}6.5 \\
5.0 \\
90.6\end{array}$ & $\begin{array}{l}0.9603 \\
0.3943 \\
0.0012\end{array}$ \\
\hline
\end{tabular}

SIS-16, the Stroke Impact Scale-16.

independent predictors of death. However, even after adjustment, there was no significant difference between the stroke-on-awakening and stroke-while-awake cohorts. When the data were analyzed by stroke type, age $(\mathrm{p}<0.0001)$ and alertness $(\mathrm{p}=0.0113$ ) continued to be predictors of death in ischemic stroke patients, but not for intracerebral or subarachnoid hemorrhage.

\section{Predictors of poor outcome}

Using the SIS-16 at six months, we developed a general linear random effects model to identify predictors of poor outcome. There were no significant differences in baseline characteristics or mortality between those patients who had a complete SIS-16 score at six months compared to those who did not. Age, gender and level of consciousness at admission were used as forced variables in the model. A single model was created for all patients, and then multiple models were categorized by stroke type. Among all stroke types, patients with stroke-on-awakening had an average SIS-16 score that was 5.1-points lower. The independent predictors of poor outcome were advanced age, low level of consciousness, and female gender. There was no significant difference in the subset of ischemic patients. Subarachnoid hemorrhage patients with stroke-on-awakening showed a SIS-16 score that was 27.5-points lower at six months. In a secondary analysis, an age by stroke-on-awakening interaction was present $(\mathrm{p}=0.025)$ such that the bad prognosis implied by stroke-on-awakening was only present among older subarachnoid hemorrhage patients.

\section{Discussion}

Stroke onset time is often unknown. In this large sample, $13.5 \%$ of patients woke up with their deficits, which is less than previous estimates. One of the reasons for this discrepancy may be that our data are based on patients who had consented for the RCSN and, therefore, it is not population-based.

In comparison to previous work, we found minor differences in baseline data between the two cohorts (Table 1). There was a significant difference in ethnic origin and blood pressure. The ethnic differences may be due in part to information biases in the assessment of stroke onset, real biological differences, or the fact that more stroke-while-awake patients were unclassified with respect to ethnicity. Higher systolic blood pressures among patients with stroke-on-awakening may indicate a biological effect of early morning blood pressure peaks.

There were no differences between the two cohorts with respect to initial level of consciousness, which was a surrogate for stroke severity. Our data supports previous findings, measured by various scales. Fink et $\mathrm{al}^{9}$ determined stroke severity by the National Institutes of Health Stroke Scale (which was not done in Phase 1 of our study, and poorly in Phase 2) and Serena et $\mathrm{al}^{2}$ measured the variable with the Canadian Neurological Scale. Canadian Neurological Scale scores determined in Phase 2 of our study weakly support Serena et al's findings $(\mathrm{p}=0.0501)$. However, Bornstein et $\mathrm{al}^{19}$ reported that strokes that occurred during sleep were more severe. That study used a three-point rating scale for stroke severity based on the ability to carry out activities of daily living, and that corroborates with our use of level of consciousness as a surrogate for stroke severity. Further, selection bias introduced by the consent process was more likely to exclude patients with severe stroke and this bias is highlighted in the low overall mortality.

The major finding of our study is that patients with stroke-onawakening were more likely to have a poor outcome at six months. The effect size was modest. Selection bias is always a factor in follow-up; however, we ensured that there were no significant differences between the complete and incomplete follow-up SIS-16 patients in baseline characteristics or mortality. A difference of $10-15$ points on the SIS-16 correlates with a difference of one point in the modified Rankin Scale. ${ }^{20}$ Although statistically significant, the median difference in SIS-16 scores was only 7.0, and it is important contextually to infer that this is a small change in functional status, equivalent to less than one point on the modified Rankin Scale. However, to support the significance of our finding on the SIS-16, we did observe that patients with stroke-on-awakening were less likely to return home, and therefore more likely to end up in long-term care.

Equally relevant is the observation that the differences in SIS16 were driven by outcome after subarachnoid hemorrhage. Patients with ischemic stroke and intracerebral hemorrhage were no more likely to suffer a poor outcome if they had had their stroke upon awakening. Importantly, mortality, both initially and at six months, as well as length of hospital stay, did not differ between the two cohorts. 
Our study has limitations inherent in large stroke registries. The RCSN cohort has a selection bias introduced by the decision to seek informed patient consent. The RCSN hospitals were not randomly chosen and included 16 large academic tertiary referral centres. These factors may limit the generalisability of the findings but do not impact on the internal comparison between stroke-on-awakening and stroke-while-awake events analysed in this study. The large sample size obtained from multiple institutions and the prospective collection of the data make this study unique.

Overall, our data support the concept that patients with strokeon-awakening are a large minority of stroke victims. The lack of substantial clinical differences at presentation and outcomes between patients with stroke-on-awakening compared to strokewhile-awake, makes this group a logical target for future studies of intervention, such as thrombolysis. Among ischemic stroke patients, Fink et $\mathrm{al}^{9}$ have already suggested that imaging may be a good technique for studying these patients and a method of identifying those who would benefit from thrombolytic therapy or other acute intervention - all without knowing the time of onset of stroke. Further study of intervention among patients with stroke-on-awakening is warranted.

\section{ACKNOWLEDGEMENTS AND FUnding}

The study was supported in part by the Canadian Stroke Network. MDH was supported by the Heart \& Stroke Foundation of Alberta/NWT/Nunavut and the Canadian Institutes for Health Research. JN was supported by a summer studentship from the Alberta Heritage Foundation for Medical Research.

\section{REFERENCES}

1. Wroe SJ, Sandercock P, Bamford J, et al. Diurnal variation in incidence of stroke: Oxfordshire community stroke project. $\mathrm{Br}$ Med J 1992;304:155-157.

2. Serena J, Davalos A, Segura T, Mostacero E, Castillo J. Stroke on awakening: looking for a more rational management. Cerebrovasc Dis 2003;16:128-133.

3. Chaturvedi S, Adams HP Jr, Woolson RF. Circadian variation in ischemic stroke subtypes. Stroke 1999;30:1792-1795.

4. Elliott WJ. Circadian variation in the timing of stroke onset: a metaanalysis. Stroke 1998;29:992-996.
5. Marsh EE 3rd, Biller J, Adams HP Jr, et al. Circadian variation in onset of acute ischemic stroke. Arch Neurol 1990;47:11781180.

6. Fujishima S, Abe I, Okada Y, et al. Serial changes in blood pressure and neurohormone levels after the onset of lacunar stroke. Angiology 1996;47:579-587.

7. Millar-Craig MW, Bishop CN, Raftery EB. Circadian variation of blood-pressure. Lancet 1978;8068:795-797.

8. Hermann DM, Bassetti CL. Sleep-disordered breathing and stroke. Curr Opin Neurol 2003;16:87-90.

9. Fink JN, Kumar S, Horkan C, et al. The stroke patient who woke up: clinical and radiological features, including diffusion and perfusion MRI. Stroke 2002;33:988-993.

10. Bassetti C, Aldrich M. Night time versus daytime transient ischaemic attack and ischaemic stroke: a prospective study of 110 patients. J Neurol Neurosurg Psychiatry 1999;67:463-467.

11. Kapral MK, Laupacis A, Phillips SJ, et al, for the Investigators of the Registry of the Canadian Stroke Network. Stroke care delivery in institutions participating in the Registry of the Canadian Stroke Network. Stroke 2004;35:1756-1762.

12. Tu JV, Willison DJ, Silver FL, et al, for the Investigators in the Registry of the Canadian Stroke Network. Impracticability of informed consent in the Registry of the Canadian Stroke Network. N Engl J Med 2004;350:1414-1421.

13. Duncan PW, Lai SM, Bode RK, Perera S, DeRosa J. Stroke Impact Scale-16: a brief assessment of physical function. Neurology 2003;60:291-296.

14. Edwards B, O'Connell B. Internal consistency and validity of the Stroke Impact Scale 2.0 (SIS 2.0) and SIS-16 in an Australian sample. Qual Life Res 2003;12:1127-1135.

15. Duncan PW, Wallace D, Lai SM, et al. The stroke impact scale version 2.0. Evaluation of reliability, validity, and sensitivity to change. Stroke 1999;30:2131-2140.

16. Stewart AL, Ware JE (Eds). Measuring Functioning and WellBeing: The Medical Outcomes Study Approach. Durham (NC): Duke University Press, 1992:

17. Henon H, Godefroy O, Leys D, et al. Early predictors of death and disability after acute cerebral ischemic event. Stroke 1995;26: 392-398.

18. Cucchiara BL, Kasner SE, Wolk DA, et al, CLASS-I Investigators. Early impairment in consciousness predicts mortality after hemispheric ischemic stroke. Crit Care Med 2004;32:241-245.

19. Bornstein NM, Gur AY, Fainshtein P, Korczyn AD. Stroke during sleep: epidemiological and clinical features. Cerebrovasc Dis 1999;9:320-322.

20. Lai SM, Perera S, Duncan PW, Bode R. Physical and social functioning after stroke: comparison of the Stroke Impact Scale and Short Form-36. Stroke 2003;34:488-493. 